\title{
Optimal allocation of distributed generation and electric vehicle charging stations based on intelligent algorithm and bi-level programming
}

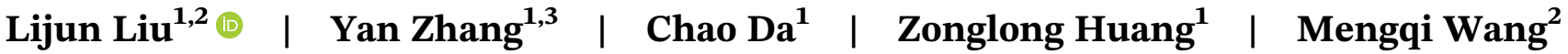

\begin{abstract}
${ }^{1}$ Department of Electrical Engineering and Automation, Fuzhou University, Fuzhou, China

${ }^{2}$ Department of Electrical and Computer Engineering, University of Michigan-

Dearborn, Dearborn, Michigan

${ }^{3}$ Fujian Smart Electrical Engineering Technology Research Center, Fuzhou University, Fuzhou, China

\section{Correspondence}

Lijun Liu, Department of Electrical Engineering and Automation, Fuzhou University, Fuzhou 350108, China.

Email: liulijun0120@fzu.edu.cn

Funding information

Fujian Natural Science Foundation of China, Grant/Award Number: 2016J01219

\section{Peer Review}

The peer review history for this article is available at https://publons.com/publon/ $10.1002 / 2050-7038.12366$.
\end{abstract}

\begin{abstract}
To facilitate the development of active distribution networks with high penetration of large-scale distributed generation (DG) and electric vehicles (EVs), active management strategies should be considered at the planning stage to implement the coordinated optimal allocations of DG and electric vehicle charging stations (EVCSs). In this article, EV charging load curves are obtained by the Monte Carlo simulation method. This article reduces the number of photovoltaic outputs and load scenarios by the K-means++ clustering algorithm to obtain a typical scenario set. Additionally, we propose a bi-level programming model for the coordinated DG and EVCSs planning problem. The maximisation of annual overall profit for the power supply company is taken as the objective function for the upper planning level. Then, each scenario is optimised at the lower level by using active management strategies. The improved harmonic particle swarm optimisation algorithm is used to solve the bi-level model. The validation results for the IEEE-33 node, PG\&E-69 node test system and an actual regional 30-node distribution network show that the bi-level programming model proposed in this article can improve the planning capacity of DG and EVCSs, and effectively increase the annual overall profit of the power supply company, while improving environmental and social welfare, and reducing system power losses and voltage shifts. The study provides a new perspective on the distribution network planning problem.
\end{abstract}

\section{KEYWOR D S}

bi-level programming model, distributed generation, electric vehicle charging station, optimal allocation

\section{1 | INTRODUCTION}

With increasing attention on environmental pollution problems and the fossil fuel crisis, an increasing number of applications are being proposed for distributed generation (DG) and electric vehicles (EVs). ${ }^{1,2}$ Furthermore, the necessary infrastructure for EVs, that is, electric vehicle charging stations (EVCSs), is being built with support from government and enterprise. However, the large-scale integration of DG and EVCSs will bring many new problems, such as increasing power losses and voltage sags during power system operation. Therefore, the planning problem of reasonably allocating DG and EVCSs is attracting much attention. 
The work by Gao et $\mathrm{al}^{3}$ uses multiobjective formulations that consider net revenue maximisation, load timing characteristics and the DG output and generates solutions with an adaptive generic algorithm. The work by Kayalvizhi and Vinod $^{4}$ builds a multiobjective optimisation model that simultaneously consider power loss minimisation, voltage shift minimisation and cost minimisation, and the validity of the programming model is verified by three examples. The work by Singh et $\mathrm{al}^{5}$ builds an optimal allocation model for DG with constraints for reactive power optimisation and network reconfiguration. The intelligent heuristic algorithm is used to obtain optimal solution. Some Traffic flow models are used in Xiang et $\mathrm{al}^{6}$ to determine the capacity of EVCSs with consideration of coupled traffic flow and load demand constraints. In other studies, such as references 7-9, the authors formulate the EVCSs planning goal as a total cost minimisation problem by considering power loss costs and EVCSs investment costs together.

The aforementioned works mainly study the planning problems of DG and EVCSs separately without considering the coupled coordination problem. In practice, the siting and sizing of EVCSs affects not only the power system stability but also the convenience of EV use. In addition, the reasonable planning of EVCSs will benefit local on-site consumption of DG power output. Based on these considerations, the work by Liu et $\mathrm{al}^{10}$ builds a joint planning model of EVCSs and renewable energy with minimum voltage fluctuations, minimum load fluctuations and maximum capacity for EVCS energy storage connections, and the genetic particle swarm algorithm is used to determine the optimal construction scheme. Other works ${ }^{11,12}$ consider the impacts of increasing the load demand, dynamic electricity pricing and DG power intermittence on the EVCS and DG coordination planning problem.

Large-scale access to renewable DG and the extensive use of EVs have promoted the use of clean energy and enhanced the sustainability of power grid development. However, at the same time, problems such as power quality declines, voltage overruns and an increase in system losses have emerged. The traditional distribution network has the problem of an outdated management mode that cannot completely solve the above problems. To effectively reduce the adverse effects of new grid-connected energy sources and improve the compatibility between these sources and the overall system, the related technologies of active distribution networks (ADNs) have received extensive attention in recent years. ADNs coordinate and control DG, the energy storage system, controllable loads and other power equipment in the distribution network by optimising the system management mode to promote the source absorption of green and clean energy. The planning models in [10-12] do not consider the adjustment ability of ADNs when considering the planning problem, and could not make full use of the positive effects of DG and EVCs on reducing network loss and improving system power flow distribution, which limited the development of DG and EVCS. The work by Zare et $\mathrm{al}^{13}$ takes active management measures for DG connected to distribution network and establishes a distributed planning model of DG based on multiobjective two-layer distribution under the active management model. The work by Bo et $\mathrm{al}^{14}$ is based on the master-slave logic structure, aiming at promoting the efficient use of intermittent DG, and established the ADN double-layer scene-planning model. The location and volume of DG and EVCS are closely related to ADN's operation control strategy. Solving the bi-level programming model is an effective means of ADN planning.

In conclusion, there are few studies on joint planning of DG and EVCS and considering active management measures. Therefore, a bi-level planning model of a coupled EVCS and DG system that considers the active management strategy of distribution network is proposed in this article. First, the daily characteristic curve of EV charging load is obtained through Monte Carlo simulation (MCS), and then the total charging load in the planned area is obtained. The $\mathrm{K}$-means++ clustering algorithm is used to construct typical scenarios for DG and conventional loads. On this basis, a two-layer model of joint coordination planning including DG and EVCS is established. The upper planning level sets the objectives of investment cost, power loss cost and environmental and social welfare and the lower level proposes three active management measures to optimise the power flow for typical scenarios. The active management at the lower level proposes three active management measures to optimize the power flow for each typical scenario. The overall problem is solved by improved harmonic particle swarm optimisation (IHPSO) and verified on IEEE-33 node and PG\&E-69 node test systems.

\section{2 | EV CHARGING MODEL AND DG OUTPUT MODEL}

\section{$2.1 \quad$ EV charging model}

There are four types of typical EVs: buses, taxis, business cars and private cars. The charging load is affected by the charging mode, battery capacity, initial state-of-charge (SOC) and other factors. The charging parameters of four types of EVs are listed in Table 1. 
The charging time is determined by the EV parameters, ${ }^{15}$ as shown in (1).

$$
T_{\mathrm{c}}=\frac{\left(\beta-S O C_{0}\right)}{\eta \cdot P_{\mathrm{c}}} \cdot E_{\mathrm{b}} \cdot 60
$$

where $T_{\mathrm{c}}$ indicates the charging time in minutes, $\beta$ indicates the percentage of batter capacity after charging, $S O C_{0}$ indicates the percentage of battery capacity before charging, $\eta$ indicates the charging efficiency, $P_{\mathrm{c}}$ indicates the charging power and $E_{\mathrm{b}}$ indicates battery capacity.

The charging behaviours of the four types of EVs are listed in Table $2 .{ }^{16}$ Buses and taxis need to charge more than two times due to their longer daily driving distances. The operating time of buses is usually 5:30 to 23:00. To ensure sufficient driving power, it is assumed that buses need to be charged twice a day. In the daytime, to avoid the rush hours of 6:30 to 9:00 and 16:30 to 18:00, the charging time is 10:00 to 16:30. During daytime operation, the time for buses to stop and charge is limited, so fast charging is adopted. During the night, according to the bus operation time, the night charging time can be assumed to be 23:00 to 5:30, and because the charging time in the night is longer, the conventional charging method can be used. Taxis are in operation for most of the day. To ensure sufficient driving power, taxis need to be charged twice a day. In the daytime, they need to be charged from 11:30 to 14:00 and from 2:00 to 5:00 during break time. The fast charging mode is chosen for the limited charging time. Because government departments or enterprises usually perform their official duties in the daytime, the official vehicles will be in the driving state only during the day. The charging time is long from 18:00 to 7:00, so conventional charging is adopted. The charging period of private cars can be divided into a night rest period at home and a daytime work period, that is, 18:00 to 7:00 and 8:00 to 17:00. The charging time is long and can be 19:00 to 22:00 at places such as supermarkets and shopping malls. Considering the shopping and entertainment needs of private EV users, short-term charging time should be applied.

This article estimates the EV charging loads based on MCS. MCS is used to obtain the daily charging load curve of EVs. The MCS is a method used to study the distribution characteristics of time series by setting up random processes, repeatedly generating time series and calculating parameter estimators and statistics. The prediction accuracy depends on the number of simulations, with more simulations resulting in more accurate predictions, and the error method has nothing to do with the dimension of the problem because the dimension error of the problem does not increase with the size of the problem. The method can be used directly to determine the statistical properties of a problem, and it does not need to handle discretisation or continuity problems. The solution process is simple and direct, and the error in the result is the error probability, which can be effectively reduced by increasing the number of simulations. Thus, this method is the most effective way or the only way to resolve some problems.

Based on MCS, the calculation process of EV charging loads is as follows:

1. randomly select the beginning charging time and initial SOC of a single EV;

2. calculate the charging limit time $T_{\text {lim }}$ based on the time period of EV charging behaviour;

3. calculate the required charging time $T_{\mathrm{f}}$ according to the fully charged expectation;

4. obtain the practical charging time $T_{\mathrm{cd}}=\min \left(T_{\text {lim }}, T_{\mathrm{f}}\right)$;

5. repeat steps 1 to 4 for all other EVs considered and

6. aggregate the total EV charging load in a certain region.

\subsection{Intermittent DG output model}

If an EV is fully charged by power generation from conventional energy sources, then the indirectly produced $\mathrm{CO}_{2}$ emissions will not be less than those of conventional vehicles. To date, the most common renewable energy resources

TA B LE 1 Charging parameters of electric vehicles

\begin{tabular}{|lcccc} 
Vehicle type & Battery capacity $(\mathbf{k W} \cdot \mathbf{h})$ & Conventional charging power $(\mathbf{k W})$ & Fast charging power $(\mathbf{k W})$ \\
\hline Bus & 200 & 21 & 135 \\
\hline Taxi & 64 & 14 & 90 & 45 \\
\hline Official car & 32 & 7 & 45 & 45 \\
\hline Private car & 32 & 7 & \\
\hline
\end{tabular}


are distributed wind generation (DWG) and photovoltaic generation (PVG), which have strong characteristics of intermittence due to the effects of solar irradiance, wind speed and other environmental factors. To choose optimal EVCS locations, we should consider the weather conditions in certain areas.

The PV power output model is

$$
P_{\mathrm{PVG}}=\left\{\begin{array}{cc}
P_{\mathrm{PVGS}} \frac{g}{g_{\mathrm{s}}} & g \leq g_{\mathrm{s}} \\
P_{\mathrm{PVGS}} & g>g_{\mathrm{s}}
\end{array}\right.
$$

where $P_{\mathrm{PVG}}$ denotes the output power of PV, $P_{\mathrm{PVGS}}$ indicates the rated output power of PV, $g$ indicates the actual solar irradiance and $g_{\mathrm{s}}$ indicates the rated solar irradiance.

Wind power is closely correlated with wind speed, and the relationship can be described as follows:

$$
P_{\text {DWG }}=\left\{\begin{array}{lr}
0 & 0 \leq v<v_{\mathrm{i}} \cup v_{\mathrm{o}} \leq v \\
P_{\mathrm{DWGS}} \frac{v-v_{\mathrm{i}}}{v_{\mathrm{s}}-v_{\mathrm{i}}} & v_{\mathrm{i}} \leq v<v_{\mathrm{s}} \\
P_{\mathrm{DWGS}} & v_{\mathrm{s}} \leq v<v_{\mathrm{o}}
\end{array}\right.
$$

where $P_{\mathrm{DWG}}$ indicates the wind output power, $P_{\mathrm{DWGS}}$ indicates the rated wind output power, $v$ indicates the actual wind speed, $v_{\mathrm{i}}$ indicates the cut-in wind speed, $v_{\mathrm{o}}$ indicates the cut-off wind speed and $v_{\mathrm{s}}$ indicates the rated wind speed.

\section{3 | Selection of typical scenarios}

The PV, wind output power and load demand have characteristics of periodicity and uncertainty. Therefore, selecting the typical scenarios according to historical data in certain areas is very important for describing the PV output power, wind output power and demand load. This article uses the K-means++ clustering algorithm ${ }^{17}$ for scenario reduction. The K-means++ algorithm has the advantages of simple implementation and good clustering, and compared with other methods, such as the K-means algorithm, this algorithm possesses a selection process of initial clustering centres by the distance maximisation principle that is conducive to improving the clustering effect. We can use 8760 hours of historical data as the original dataset for the PV, wind power and load demand and then divide these 365 daily curves into k scenarios according to the Pseudo F-statistic (PFS) metric. ${ }^{18}$ The k scenarios selected are denoted as $\xi_{1}, \xi_{2}, \ldots, \xi_{\mathrm{k}}$. The DG output is calculated according to these $\mathrm{k}$ scenarios. The clustering process is as follows:

1. Normalisation of PV, wind power and load demand based on the data standardisation method;

2. Based on the maximum distance between initial clustering centres, $\mathrm{K}$ clustering centres are initialised. The steps are as follows:

a. A scene from the original scene set $N_{i}, i=1,2,3, \ldots, 365$ is randomly selected as the first cluster $\xi_{1}$.

b. The shortest Euclidean distance $d\left(N_{i}, \xi_{j}\right)$ between each original scene and the existing clustering centres is calculated, and $d\left(N_{i}, \xi_{j}\right)$ of each original scene is accumulated to get the accumulated value sum $(d)$.

c. The random value rand, rand $<\operatorname{sum}(d)$ is generated, and the rand value is updated to rand $d\left(N_{i}, \xi_{j}\right)$. When ran$\mathrm{d}<0, N_{i}$ is the new cluster centre, which ensures that the original scene farther from the existing cluster centre is selected as the new cluster centre.

d. Steps 2 and 3 are repeated until the selection of $k$ clustering centres $\xi_{1}, \xi_{2}, \ldots, \xi_{\mathrm{k}}$ is completed.

e. The Euclidean distance from the remaining original scene to $\mathrm{k}$ clustering centres is calculated, and the original scene is divided into the nearest clustering cluster.

f. The centres of $\mathrm{k}$ clusters are calculated, and the $\mathrm{k}$ centres to the new generation of clustering centres of $\xi_{1}, \xi_{2}, \ldots, \xi_{\mathrm{k}}$ are updated.

g. Steps 3 and 4 are updated until the clustering results do not change. 
TAB LE 2 Charging behaviour of electric vehicles

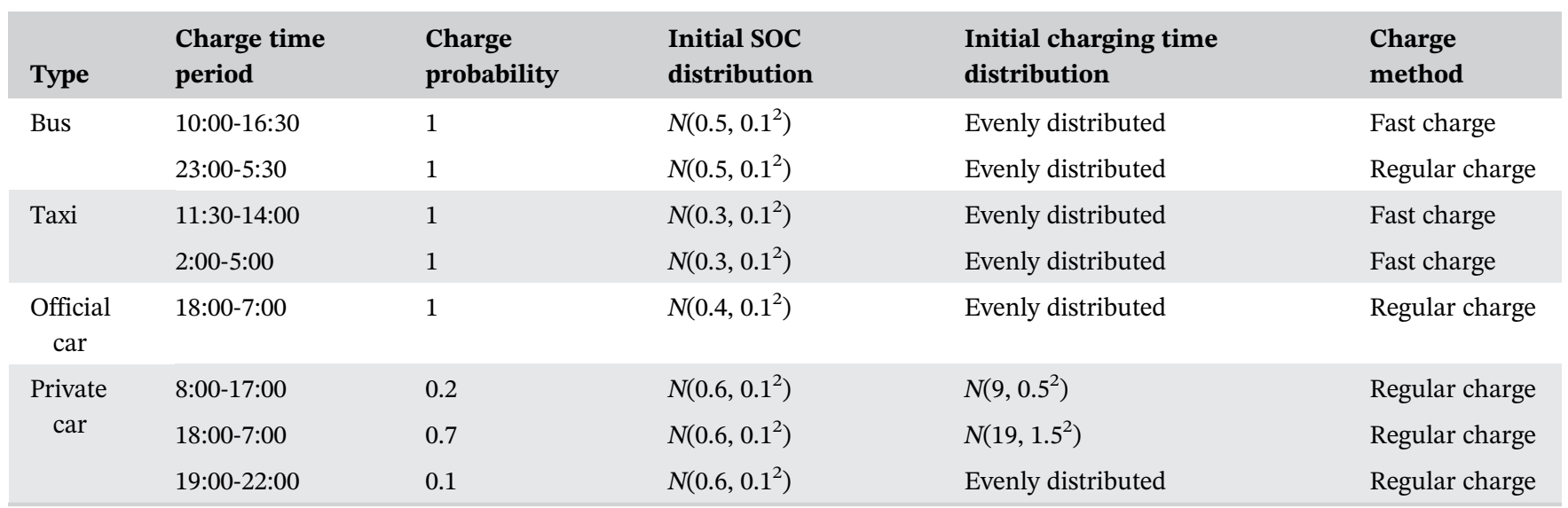

\section{3 | MATHEMATICAL FORMULATION WITH BI-LEVEL PROGRAMMING}

A bi-level programming model is a hierarchical system optimisation model in which the upper and lower levels have their own mathematical models. ${ }^{19,20}$ The lower-level programming problem is based on the scheme given by the upperlevel decision-making process. The optimal value of the lower-level decision-making process is fed back to the upper level, and the upper-level decision-making process conforms to the global optimal benefit according to the optimal value response of lower-level decision-making process. Bi-level programming is characterised by considering the entire situation from a holistic point of view, which is conducive to achieving the global optimum.

\section{1 | The planning level model}

It is assumed that the investment in intermittent DG and EVCSs comes from a power supply company. The decision variables of the upper planning level will be location and capacity, and the objective is the maximisation of annual revenue with considerations for the annual rate of return, power loss and environmental and social welfare. The objective function is shown in (4).

$$
\max F=C_{\text {pro }}-C_{\text {loss }}+C_{\text {env }}
$$

where $C_{\text {pro }}$ indicates the annual rate of return for the power supply company, $C_{\text {loss }}$ indicates the power loss and $C_{\text {env }}$ indicates the environmental and social welfare. The three cost structures are listed as follows:

1. The annual rate of return for the power supply company $C_{\text {pro }}$ is given by

$$
C_{\text {pro }}=C_{\mathrm{S}}+C_{\mathrm{B}}-C_{\mathrm{inv}}-C_{\mathrm{OM}}
$$

where $C_{\mathrm{s}}$ indicates the profit of the power supply company, $C_{\mathrm{B}}$ indicates government subsidies for renewable energy sources, $C_{\text {inv }}$ indicates the investment in intermittent DG and EVCSs and $C_{\mathrm{OM}}$ indicates the maintenance fee for DG and EVCSs.

$$
\begin{aligned}
C_{\mathrm{S}}= & 365 \sum_{l=1}^{k} p_{l} \sum_{t=1}^{24}\left(c_{\mathrm{o}}\left(P_{l, t, \mathrm{DWG}}+P_{l, t, \mathrm{PVG}}\right)+\left(c_{\mathrm{o}}-c_{\mathrm{i}}\right) .\right. \\
& \left.\left(P_{l, t, L}-P_{l, t, \mathrm{DWG}}-P_{l, t, \mathrm{PVG}}\right)+\left(c_{\mathrm{e}}-c_{\mathrm{i}}\right) P_{l, t, \mathrm{EV}}\right),
\end{aligned}
$$

where $k$ indicates the number of typical scenarios; $p_{l}$ indicates the probability of the $l$ th typical scenario; $c_{\mathrm{i}}$ and $c_{\mathrm{o}}$ indicate the purchasing and selling prices for the power supply company; $c_{\mathrm{e}}$ indicates the unit selling price for EVCSs; and 
$P_{l, t, \mathrm{~L}}, P_{l, t, \mathrm{DWG}}, P_{l, t, \mathrm{PVG}}$ and $P_{l, t, \mathrm{EV}}$ represent the load demand, DWG output power, PVG active power and EVCS charging load, respectively, at time interval $t$.

$$
C_{\mathrm{B}}=365 \sum_{l=1}^{k} p_{l} \sum_{t=1}^{24} c_{\mathrm{b}, \mathrm{DWG}} P_{l, t, \mathrm{DWG}}=c_{\mathrm{b}, \mathrm{PVG}} P_{l, t, \mathrm{PVG}}
$$

where $c_{\mathrm{b}, \mathrm{DWG}}$ and $c_{\mathrm{b}, \mathrm{PVG}}$ represent units of government subsidies for DWG and PVG.

$$
C_{\mathrm{inv}}=\left(\sum_{j=1}^{n_{\mathrm{DWG}}} c_{\mathrm{t} 1} P_{j, \mathrm{DWG}}+\sum_{j=1}^{n_{\mathrm{PVG}}} c_{\mathrm{t} 2} P_{j, \mathrm{PVG}}+\sum_{j=1}^{n_{\mathrm{EV}}}\left(c_{g}+c_{t 3} P_{j, E V}\right)\right) \frac{r(1+r)^{n_{1}}}{(1+r)^{n_{1}}-1}
$$

where $C_{\mathrm{inv}}$ indicates the investment and building costs of DG and EVCSs; $n_{\mathrm{DWG}}, n_{\mathrm{PVG}}$ and $n_{\mathrm{EV}}$ indicate the number of candidate nodes for DWG, PVG and EVCSs, respectively; $P_{j, \mathrm{DWG}}, P_{j, \mathrm{PVG}}$ and $P_{j, \mathrm{EV}}$ indicate the capacity for DWG, PVG and EVCSs, respectively, at node $j ; c_{\mathrm{t} 1}, c_{\mathrm{t} 2}$ and $c_{\mathrm{t} 3}$ indicate the unit capacity construction costs of DWG, PVG and EVCSs, respectively; $c_{\mathrm{g}}$ indicates the fixed investment cost of EVCSs; $r$ indicates the discount rate and $n_{1}$ indicates the service life of the equipment.

$$
C_{\mathrm{OM}}=365 \sum_{l=1}^{k} p_{l} \sum_{t=1}^{24}\left(c_{\mathrm{om} 1} P_{l, t, \mathrm{DWG}}+c_{\mathrm{om} 2} P_{l, t, \mathrm{PVG}}\right)+\sum_{j=1}^{n_{\mathrm{EV}}}\left(c_{\mathrm{om} 3} P_{j, \mathrm{EV}}\right)
$$

where $c_{\mathrm{om} 1}$ and $c_{\mathrm{om} 2}$ indicate the unit maintenance fees for DWG and PVG, respectively, and $c_{\mathrm{om} 3}$ indicates the amortised unit maintenance fee for EVCSs.

2. The power loss cost $C_{\text {loss }}$ is given by

$$
C_{\text {loss }}=365 \sum_{l=1}^{k} p_{l} \sum_{t=1}^{24} c_{0} P_{l, t, \text { loss }}
$$

where $P_{l, t, \text { loss }}$ indicates the system loss at time interval $t$.

3. The environmental and social welfare $C_{\text {env }}$ is given by

$$
\begin{gathered}
E_{\mathrm{S}}=365 \sum_{l=1}^{k} p_{l} \sum_{t=1}^{24}\left(P_{l, t, \mathrm{DWG}}+P_{l, t, \mathrm{PVG}}\right) \\
C_{\mathrm{env}}=E_{\mathrm{S}} \sum_{s=1}^{N_{\mathrm{env}}} x_{s}\left(a_{s}+b_{s}\right)+365 \sum_{l=1}^{k} p_{l} \sum_{t=1}^{24} \frac{P_{l, t, \mathrm{EV}}}{e_{\mathrm{EV}}} c_{\mathrm{Co}_{2}} x_{\mathrm{EV}},
\end{gathered}
$$

where $E_{\mathrm{s}}$ indicates the output power for renewable energy; $C_{\mathrm{env}}$ indicates the social welfare of renewable energy sources and reduced emissions from EVs; $N_{\text {env }}$ indicates the types of pollution gases; $x_{s}, a_{s}$ and $b_{s}$ denote the emission levels of the sth kind of pollution gas; $e_{\mathrm{EV}}$ indicates the energy consumed by an EV in 100 miles; $c_{\mathrm{CO}_{2}}$ indicates the $\mathrm{CO}_{2}$ trading tax fee in the international market; and $x_{\mathrm{EV}}$ indicates the difference between EVs and conventional vehicles.

The constraints in the upper-level optimisation model are

$$
\begin{gathered}
P_{\mathrm{DG} i, \text { min }} \leq P_{\mathrm{DG} i} \leq P_{\mathrm{DG} i \text { max }} \\
\sum_{i=1}^{n_{\mathrm{DG}}} P_{\mathrm{DG} i} \leq P_{\mathrm{DG}, \max }
\end{gathered}
$$




$$
P_{\mathrm{EV} i \text { min }} \leq P_{\mathrm{EVi}} \leq P_{\mathrm{EV} i \text { max }}
$$

\section{2 | The active management level model}

The lower active management level is based on the upper-level planning decisions, and three active management strategies are proposed for power flow optimisation in typical scenarios, including transformer adjustment, DG output curtailment and reactive power compensation. The curtailment rate of DG is $0 \%$ to $30 \%$, the transformer adjustments are $1 \% \pm 1.25 \% * 8$ and are installed at the system header node, and the reactive power compensation is 50 kvar for a unit capacity with 0 to 10 units. Power flow optimisation based on active management measures impacts network losses, voltage levels, transmission power and other constraints of system operation and thus affects the ability of a system to accept DG and EVCSs. The above effects are ultimately reflected in the objective function. The objective function of the lower-level optimisation model is

$$
\max f=C_{l, \mathrm{~S}}+C_{l, \mathrm{~B}}-C_{l, \mathrm{OM}}-C_{l, \mathrm{loss}}+C_{l, \mathrm{env}}
$$

where $C_{l, \mathrm{~S}}, C_{l, \mathrm{~B}}, C_{l, \mathrm{OM}}, C_{l, \text { loss }}$ and $C_{l, \text { env }}$ denote the profit of the power supply company, the government subsidy for renewable energy sources, the maintenance fee for DG and EVCSs, the power loss fee and the environmental and social welfare in scenario $l$, respectively.

$$
\begin{aligned}
& \left\{\begin{array}{l}
P_{i}-U_{i} \sum_{j \in i} U_{j}\left(G_{i j} \cos \theta_{i j}+B_{i j} \sin \theta_{i j}\right)=0 \\
Q_{i}-U_{i} \sum_{j \in i} U_{j}\left(G_{i j} \sin \theta_{i j}-B_{i j} \cos \theta_{i j}\right)=0
\end{array}\right. \\
& U_{i \min } \leq U_{i} \leq U_{i \max } \\
& S_{i j} \leq S_{i j \max } \\
& U_{\text {OLTC }}^{\min } \leq U_{\text {OLTC }} \leq U_{\text {OLTC }}^{\max } \\
& P_{\text {cut } i} \leq P_{\text {cut } i}^{\max } \\
& Q_{\mathrm{c} i} \leq Q_{\mathrm{c} i}^{\max },
\end{aligned}
$$

where $P_{i}$ and $Q_{i}$ indicate active power and reactive power injections; $U_{i}$ and $U_{j}$ indicate the voltages at nodes $i$ and $j$, respectively; $G_{i j}$ and $B_{i j}$ indicate conductance and admittance, respectively; $\theta_{i j}$ indicates the angle shift between $i$ and $j$; $U_{i \max }$ and $U_{i \min }$ indicate the upper and lower voltage bounds, respectively, at node $i ; S_{i j}$ and $S_{i j \max }$ indicate the transmission power and transmission power limit, respectively; $U_{\mathrm{OLTC}}$ indicates the secondary voltage at the transformer; $U_{\mathrm{OLTC}}^{\max }$ and $U_{\mathrm{OLTC}}^{\min }$ indicate the upper and lower limits of secondary voltage at the transformer, respectively; $P_{\text {cut } i}$ indicates the curtailment for DG at node $i$; $P_{\text {cut } i}^{\max }$ indicates the allowed curtailment at node $i$ and $Q_{\mathrm{c} i}$ indicates the reactive power compensation at node $i$ with an allowed upper limit of $Q_{c i}^{\max }$.

\section{4 | THE OPTIMAL SOLUTION OF THE PROPOSED BI-LEVEL PROGRAMMING METHOD}

\section{1 | The solution algorithm for the two-layer model}

Particle swarm optimisation (PSO) simulates the principle of bird swarm foraging. It has the advantages of simple calculation and strong direction of optimisation. However, the PSO algorithm has poor global search ability and easily falls into local optima in the later stage of the algorithm. Harmony search (HS) expands the search range in the later stage 
of the algorithm, but its directivity is not strong. The new harmony combination principle of the HS algorithm is introduced in the particle optimisation process of the PSO algorithm. In each iteration of the process, the search space is searched for the optimal particle with a certain probability to improve the global search performance of the algorithm. The computational steps of IHPSO algorithm are as follows:

1. Chaotic initialisation of PSO based on formula (23) is used to improve the ergodicity of the initial particle in the search space:

$$
\begin{gathered}
x_{i, j}=x_{j}^{\min }+\left(x_{j}^{\max }-x_{j}^{\min }\right) \chi_{i, j} \\
\chi_{i, j+1}=\lambda \cdot \chi_{i, j}\left(1-\chi_{i, j}\right),
\end{gathered}
$$

where $x_{i, j}$ indicates the $j$-dimension of particle $i ; x_{j}^{\max }$ and $x_{j}^{\min }$ indicate the upper and lower limit values, respectively, of variable $j$; and $\chi_{i, j}$ indicates the sequences of chaotic variables generated by logistic mode 1 , and the chaotic parameters $\lambda$ are set to 4 .

2. The fitness value $f\left(x_{i}\right)$ of each particle is calculated, and the individual extreme value $P_{i}$ of each particle and the global extreme value $P_{\mathrm{g}}$ of the population are obtained.

3. The inertia coefficient, learning coefficient and particle position and velocity are updated.

4. The fitness value of the new generation particle swarm is calculated, the individual extreme value is updated, and the global extreme value is removed.

5. New particles $h m^{\text {new }}$ are generated based on Harmony Memory Considering Rate (HMCR), Pitch Adjusting Rate $(P A R)$, and bandwidth $(B W)$.

a. If $H M C R$ is larger than the random variable, new particle variables are randomly obtained from PSO; otherwise, they are randomly generated from the range of variables.

b. If $P A R$ is greater than the random variable, then the bandwidth of the new particle variable is adjusted; otherwise, no adjustment is made.

c. Steps (b) and (c) are repeated until all new variables are constructed to generate new particles.

6. The global extremum $P_{\mathrm{g}}$ is updated. If the fitness value of the new harmony $f\left(h m^{\text {new })}\right.$ is better than the fitness value of the global extremum $f\left(P_{\mathrm{g}}\right)$, then the new harmony $h m^{\text {new }}$ is the new global extremum $P_{\mathrm{g}}$.

7. Whether the algorithm satisfies the conditions for achieving the number of iterations is determined; otherwise, return to step 3.

\section{2 | The flowchart of the solution process}

The coordinated bi-level programming framework for DG and EVCSs is presented in Figure 1. The planning level determines the siting and sizing of DG and EVCSs, and the active management level determines the three active management strategies by using transformer adjustment, DG output curtailment and reactive power compensation. The planning layer transfers the optimal allocation scheme of DG and EVCSs to the active management level. On this basis, the active management level optimises the power flow of four scenarios under the optimal allocation scheme by adjusting the On-load tap changer (OLTC) gear, reducing DG active power and switching reactive power compensation devices. By satisfying the reliability of system operation, the optimal solutions $\max f_{1} \sim \max f_{4}$ of four scenarios is obtained and fed back to the planning level. Combining the optimal solutions $\max f_{1} \sim \max f_{4}$ and the investment and construction costs of the DG and charging stations, the planning level calculates the optimal solution $\max F$ and optimises the decision scheme. By analogy, the optimal joint planning scheme of DG-charging station is determined through multiple information transmissions and feedback between the planning level and the active management level. 


\section{5 | CASE STUDY}

\subsection{Case study of the IEEE-33 node test system}

This article considers the coordinated planning problem for DG and EVCSs on an IEEE-33 node test system, which is shown in Figure 2, using the system parameters described in. ${ }^{21}$

It is assumed that the number of EVs is 600 in the studied region, the running time for the MCS is 50000 , and the parameters of the probability model are shown in Table 2 . The ratio of electric buses, electric taxis, electric buses and electric private cars is 1:2.4:10.2:63.5, as in reference [16]. The average charging load of 60 minutes in the hour is used as the charging load of an hour. According to the calculation presented in section A, the total charging load is shown in Figure 3.

The $365^{*} 24$-hour daily profiles of wind speed, solar irradiance, and conventional load demand are presented in Figure 4 in references 22, 23.

According to the PFS metric (Figure 5) of the clustering results, the number of clusters is set to be 4 . The four typical scenarios of wind speed, solar irradiance and conventional load demand are shown in Figure 6, in which normalisation has been completed.

$$
\mathrm{PFS}=\frac{\operatorname{tr}\left(N_{\mathrm{B}}\right) /(K-1)}{\operatorname{tr}\left(N_{\mathrm{W}}\right) /(S-K)}
$$

where $K$ is the number of clusters; $S$ is the number of original scene samples and $\operatorname{tr}\left(N_{\mathrm{B}}\right)$ and $\operatorname{tr}\left(N_{\mathrm{W}}\right)$ are the traces of the interclass and intraclass scatter matrices, respectively. After clustering, if the distance between different clusters is larger and the distance between samples in the same cluster is smaller, then the PFS index is larger, which indicates that the clustering effect is better.

The particle swarm size is 40 , the number of iterations time is 100 , the inertia coefficients $\omega_{\max }=0.95$ and $\omega_{\min }=0.4$, learning coefficient $c_{1 \max }=2.75, c_{1 \min }=1.25, c_{2 \max }=2.25$ and $c_{2 \min }=0.5$. In harmony algorithm part, the memory library value probability $H M C R=0.9$, the fine-tuning probabilities $P A R_{\max }=0.4$, and $P A R_{\min }=0.9$, and the finetuning bandwidths $b w_{\max }=1$ and $b w_{\min }=0.0001$. The wind turbines are installed at nodes 13, 23 and 31; the PV panels are installed at 7, 21, 28; and the EVCS candidate nodes are nodes 20, 4, 8, 14 and 29. The rated power for DG is $100 \mathrm{~kW}$, with a rated solar irradiance of $1 \mathrm{~kW} / \mathrm{m}^{2}$, and a cut-in wind speed, rated wind speed and cut-off wind speed of $3 \mathrm{~m} / \mathrm{s}, 13.5 \mathrm{~m} / \mathrm{s}$ and $20 \mathrm{~m} / \mathrm{s}$, respectively. The purchasing and selling prices of the power supply company are 0.4 $\mathrm{CNY} /$ China Yuan $(\mathrm{RMB}) / \mathrm{kW} \cdot \mathrm{h}$ and $0.5 \mathrm{RMB} / \mathrm{kW} \cdot \mathrm{h}$. The unit price of a charging station is $1 \mathrm{RMB} / \mathrm{kW} \cdot \mathrm{h}$. The government subsidy price $C_{\mathrm{b}, \mathrm{DWG}}$ is $0.1 \mathrm{RMB} / \mathrm{kW} \cdot \mathrm{h}$, and $C_{\mathrm{b}, \mathrm{PVG}}$ is $0.36 \mathrm{RMB} / \mathrm{kW} \cdot \mathrm{h}$.

The building costs are $c_{\mathrm{t} 1}=5381 \mathrm{RMB} / \mathrm{kW}, c_{\mathrm{t} 2}=4375 \mathrm{RMB} / \mathrm{kW}, c_{\mathrm{t} 3}=6000 \mathrm{RMB} / \mathrm{kW}$ and $c_{\mathrm{g}}=3000000 \mathrm{RMB}$. The discount rate is $8 \%$, and the equipment life is 20 years. The cost parameters for operation and maintenance are $c_{\mathrm{om} 1}=0.0296 \mathrm{RMB} / \mathrm{kW} \cdot \mathrm{h}, c_{\mathrm{om} 2}=0.0096 \mathrm{RMB} / \mathrm{kW} \cdot \mathrm{h}$ and $c_{\mathrm{om} 3}=100000 \mathrm{RMB} / \mathrm{MW}$ in in reference [23].

The pollution costs of thermal power generation are shown in Table 3, as in reference [24].

Three strategies are employed for optimal allocation.

- Strategy 1: use the active management strategy for the coordinated planning of DG and EVCSs.

- Strategy 2: do not use the active management strategy for the coordinated planning of DG and EVCSs.

- Strategy 3: use the optimal allocation for DG and then for EVCSs.

The results from using these three strategies are shown in Table 4.

In the DG planning scheme, 13(8) indicates that 8 distributed generators are installed in nodes 13, and in the EVCSs planning scheme, 20(237) indicates that the capacity of the charging station in node 20 is $237 \mathrm{~kW}$.

The active management measures of Strategy 1 are shown in Table 5.

In the curtailment rate of DG, $13(23 \%)$ indicates that the active outputs of DG on node 13 are reduced by $23 \%$. In the reactive power compensation, 13(400) indicates that $400 \mathrm{kvar}$ of reactive power are compensated in node 13 . In the transformer adjustments, -3 indicates that the transformer tap is connected at $-3 \times 1.25 \%$.

1. Result analysis of optimal allocation

Strategy 2 considers coordinated planning for DG and EVCSs, and strategy 3 considers DG planning first and then 

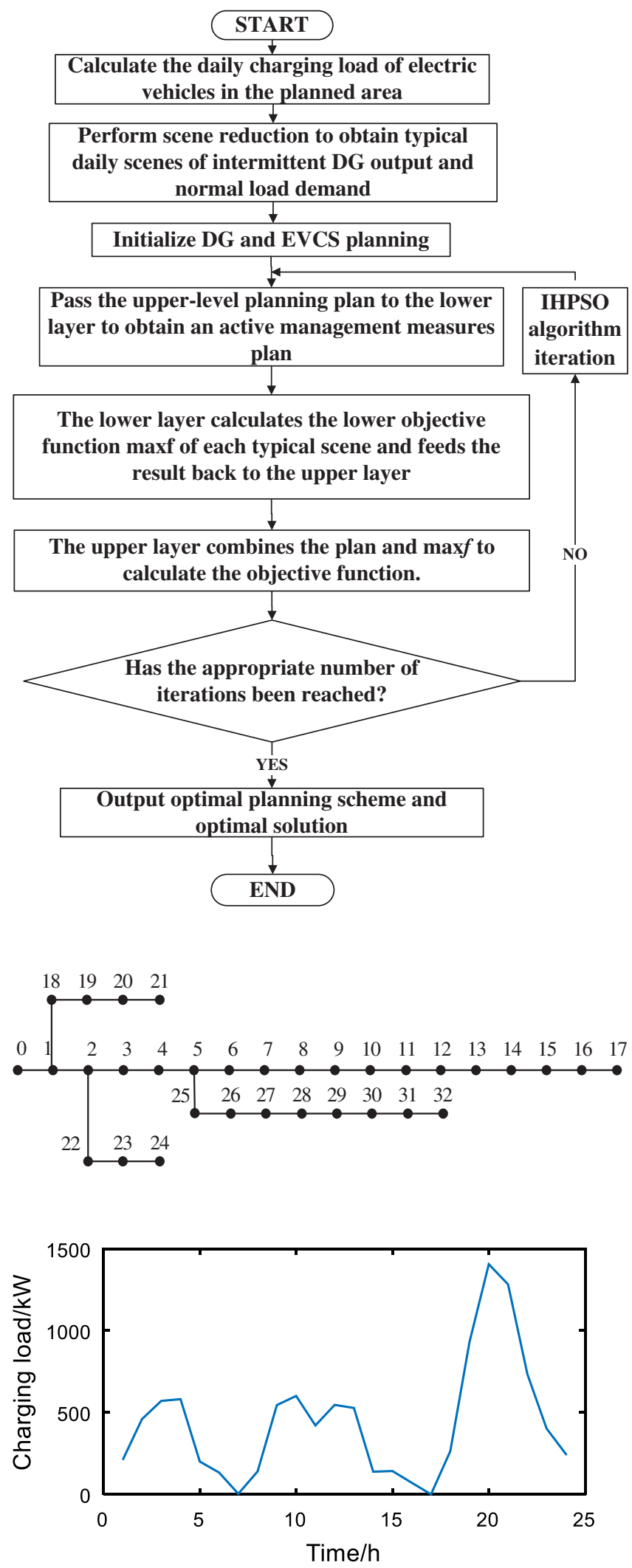

F I G URE 1 Flowchart of the bi-level programming model
FI G URE 2 IEEE-33 node test system

FIG URE 3 Charging load of an electric vehicle

allocates EVCSs based on the DG planning result. Comparing strategy 2 to strategy 3, strategy 2 increases the DG capacity to $300 \mathrm{~kW}$ because it considers mutual support for the DG and EV charging loads.

The integration of EVs into the distribution network can help to increase system flexibility by integrating DG and to reduce the possibility of voltage violations caused by DG integration. However, strategy 3 is individual planning strategy, which is limited by the designed capacity. 
F I G U RE 4 Wind speed, light intensity and load curves
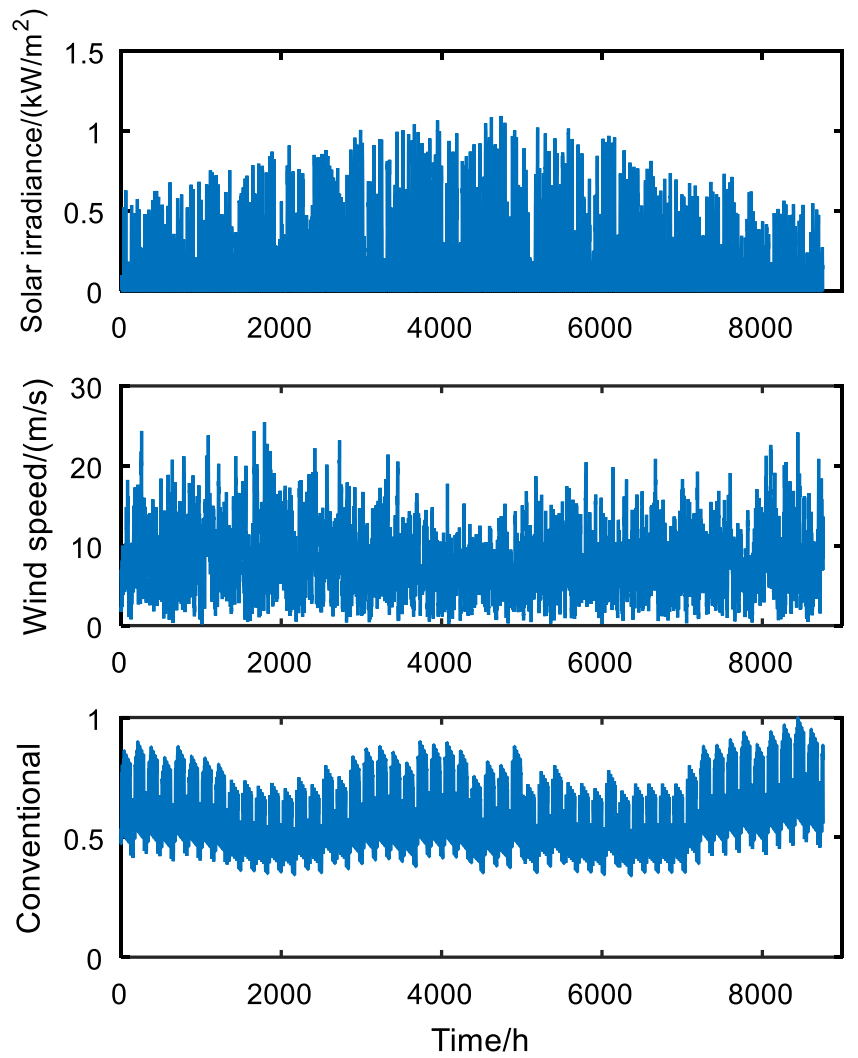

F I G U R E 5 PFS of different clustering scene numbers

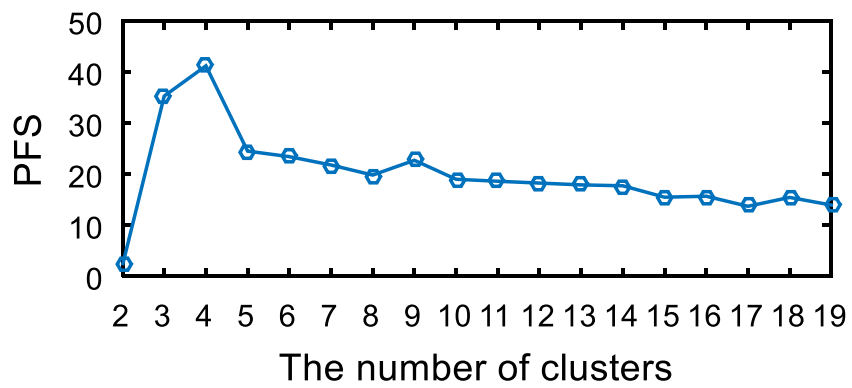

By comparing strategy 1 to strategy 2, we find that the introduction of an active management strategy increases the DG capacity by $1300 \mathrm{~kW}$ and the EVCS capacity by $150 \mathrm{~kW}$. It is believed that the use of active management strategies for DG and EVCS operation can effectively control the allocation of power flow by increasing system flexibility to integrate DG and EVCSs while satisfying various constraints in the distribution network. In traditional methods, the system could easily present some voltage or power violations for the integration of large-scale DG and EVCSs.

2. Revenue analysis of distribution network

The revenues from the distribution network using different strategies are summarised in Table 6. Comparing strategy 1 to strategy 2, strategy 1 increases the annual revenue by 654100 RMB, with annual profit increases of 445900 $\mathrm{RMB}$, power loss decreases of $94300 \mathrm{RMB}$ and environmental and social welfare increases of $113900 \mathrm{RMB}$.

a. Regarding the annual profit from the selling price, strategy 1 effectively increases the capacity of DG and EVCSs. Although increasing the capacity increases the investment and system maintenance fees, more DG output can also be consumed. The lower level power supply company will reduce the cost of purchasing electricity from the upper-level power supply company. Furthermore, EVCSs can be more effectively integrated into the power system, with increasing profits for the charging stations. Therefore, strategy 1 will have better annual profits.

b. The annual power losses caused by these three strategies are presented in Figure 7, in which strategy 1 decreases the power loss by $50.72 \%$ and $53.09 \%$ compared to strategy 2 and strategy 3 , respectively. Because strategy 1 uses active 


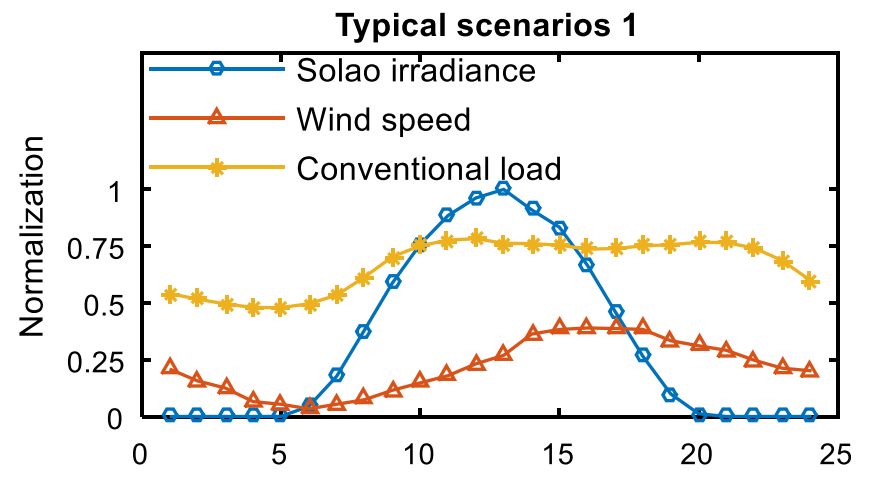

Typical scenarios 2
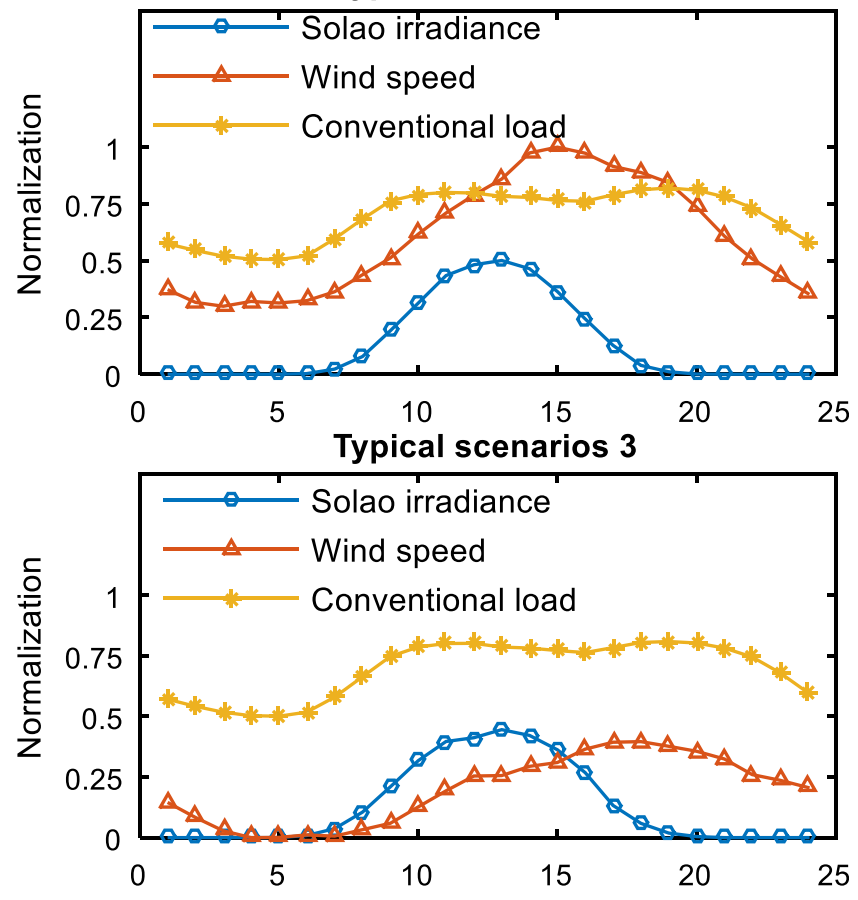

Typical scenarios 4

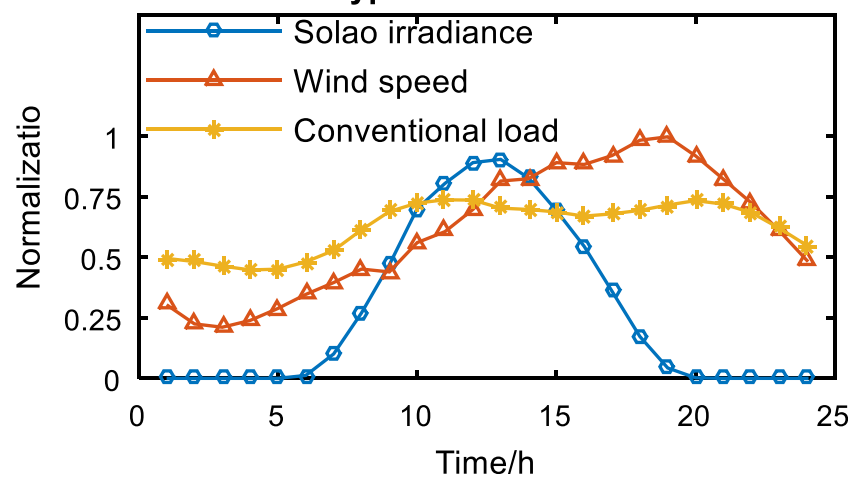

F I G U R E 6 Wind speed, light intensity and load scenarios

management for optimising power flow allocation, the power losses in the distribution network are effectively controlled.

c. Regarding clean energy utilisation, strategy 1 consumes $1870 \mathrm{MW} \cdot \mathrm{h}$ more DG output power and integrates 85.14 MW.h more EV charging loads than strategy 2, which encourages the consumption of clean energy while reducing the environmental pollution caused by fossil fuels. The emissions of $\mathrm{SO}_{2}, \mathrm{NO}_{x}$ and $\mathrm{CO}_{2}$ are reduced by $6707 \mathrm{~kg}, 2887 \mathrm{~kg}$ and $1.20 \times 10^{6} \mathrm{~kg}$, respectively, which satisfies the requirements of the Chinese government. The integration capability of clean energy and the pollution reduction ability of different strategies are presented in Table 7. 
TABLE 3 Cost parameters of environmental pollution

$\begin{array}{lcll}\text { Contaminant } & \boldsymbol{x}_{\boldsymbol{s}}(\mathbf{k g} / \mathbf{M W} \cdot \mathbf{h}) & \boldsymbol{a}_{\boldsymbol{s}}(\mathbf{R M B} / \mathbf{k g}) & \boldsymbol{b}_{\boldsymbol{s}}(\mathrm{RMB} / \mathbf{k g}) \\ \mathrm{CO}_{2} & 639.2 & 0.01 & 0.02 \\ \mathrm{SO}_{2} & 3.587 & 1.00 & 6.00 \\ \mathrm{NO}_{x} & 1.544 & 2.00 & 8.00\end{array}$

TA B L E 4 Optimal allocation results of different strategies

\begin{tabular}{|llll}
\hline Strategy & \multicolumn{2}{l}{ Optimised configuration results } & Capacity (kW) \\
\hline Strategy 1 & DG & $13(8) \cdot 23(10) \cdot 31(10) \cdot 7(7) \cdot 21(2) \cdot 28(6)$ & 4300 \\
& EVCS & $20(237) \cdot 4(194) \cdot 8(223) \cdot 14(309) \cdot 29(203)$ & 1166 \\
\hline Strategy 2 & DG & $13(10) \cdot 23(5) \cdot 31(8) \cdot 7(7)$ & 3000 \\
& EVCS & $20(252) \cdot 4(197) \cdot 8(186) \cdot 14(173) \cdot 29(208)$ & 1016 \\
\hline Strategy 3 & DG & $13(9) \cdot 23(4) \cdot 31(10) \cdot 21(3) \cdot 28(1)$ & 2700 \\
& EVCS & $20(185) \cdot 4(186) \cdot 8(185) \cdot 14(184) \cdot 29(185)$ & 925 \\
\hline
\end{tabular}

T A B L E 5 The active management measures of strategy 1

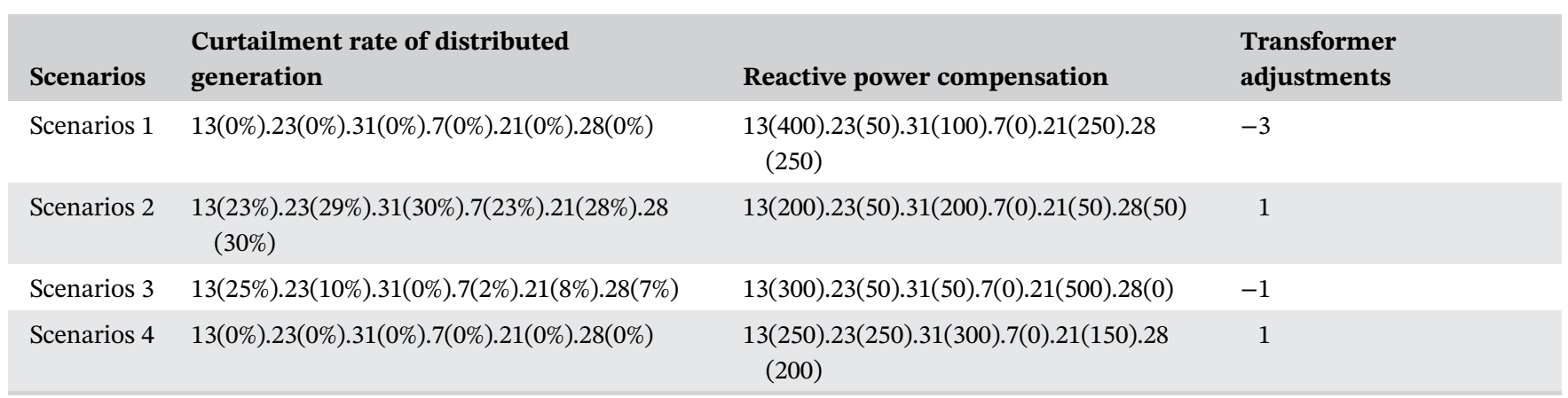

As seen by comparing strategy 2 to strategy 3, strategy 2 considers the integration capability of EVCSs for DG. Therefore, the DG output power consumption is increased by $410.47 \mathrm{MW} \cdot \mathrm{h}$ in strategy 2 , with an annual profit increase of $178900 \mathrm{RMB}$. The emissions of $\mathrm{SO}_{2}, \mathrm{NO}_{x}$ and $\mathrm{CO}_{2}$ are reduced by $1472 \mathrm{~kg}, 633 \mathrm{~kg}$ and $0.26 \times 10^{6} \mathrm{~kg}$, respectively.

d. Voltage shift analysis

For the analysis of voltage shift in the active management strategy, strategy 1 for the optimal allocation of DG and EVCSs has two results, which correspond to the cases of considering active management (case a) and not considering active management (case [b]). The absolute values of the maximum voltage shift are presented in Figure 8.

Using $\pm 5 \%$ as the limit for node voltage shifts, without the active management strategy, nodes $9 \sim 17$ and $28 \sim 32$ will have voltage limit violations, with a maximum voltage shift of $6.47 \%$. The maximum voltage deviation occurs at node 17 for the 4 typical scenarios, and its 24-hour voltage is shown in Figure 9. Voltage overshoot occurs at 9:00, 10:00, 19:00, 20:00, 21:00 and 22:00. If active management is utilised, the voltage shifts of all nodes are below 5\%, with a maximum value of $2.88 \%$. The results demonstrate that, in the scenario of high penetration of DG and EVCSs, the active management strategy can help to reduce the possibility of voltage violations and increase system reliability.

In conclusion, the comparison between strategy 2 and strategy 3 shows that the joint planning of DG and EVCSs is beneficial to the mutual absorption of DG output and EV charging loads and the development of new energy sources. Thus, strategy 2 is superior to strategy 3. By comparing strategy 1 and strategy 2, it can be concluded that in the joint planning of DG and EVCSs, considering active management measures can effectively improve the system's DG and electricity performance. The acceptance capacity of electric vehicle charging loads can meet the needs of distribution companies while reducing environmental pollution and achieving a win-win situation between enterprise interests and environmental protection. Therefore, strategy 1 is superior to strategy 2, and strategy 1 is the best of the three strategies. 


\subsection{Case study of the PG\&E-69 node test system}

To validate the optimised configuration model proposed in this article, the PG\&E-69 node test system shown in Figure 10 and the real 30-node distribution system shown in Figure 11 are verified and analysed. The parameters of the two systems are shown in references [25, 26].

For the PG\&E-69 node test system, the wind turbines are installed at nodes 10, 33 and 38, the PV panels are installed at 21, 50, 66, and the EVCS candidate nodes are nodes 14, 32, 40, 45 and 61. The planning results and the active management measures of strategy 1 are shown in Tables 8 and 9. The revenues from the distribution network using different strategies are shown in Table 10.

For the real 30-node system, the wind turbines are installed at nodes $8 \sim 14$, the PV panels are installed at nodes $23 \sim 29$, and EVCS candidate nodes are set as nodes 5, 8, 16, 22 and 25. The planning results and the active management measures of strategy 1 are shown in Tables 11 and 12. The revenues from the distribution network by using different strategies are shown in Table 13.

To analyse the voltage shift in the active management strategy, strategy 1 for the optimal allocation of DG and EVCSs has two results, which correspond to the cases of considering active management (case [a]) and not considering active management (case [b]).The absolute values of the maximum voltage shift are presented in Figures 12 and 13.

TAB L E 6 Comprehensive income of different strategies

\begin{tabular}{|lccc|}
\hline & Strategy 1 & Strategy 2 & 354.65 \\
\hline Investment and construction cost/10 000 RMB & 449.83 & 374.68 & 38.44 \\
\hline Operation and maintenance cost/10 000 RMB & 44.52 & 130.28 & 115.50 \\
\hline Government subsidy fee/10 000 RMB & 174.35 & 621.29 & 694.87 \\
\hline Distribution network sales revenue/10 000 RMB & 696.09 & 252.50 & 248.03 \\
\hline Charging station sales revenue/10 000 RMB & 258.46 & 589.95 & 18.59 \\
\hline Annual comprehensive sales revenue/10 000 RMB & 634.54 & 72.33 & 675.62 \\
\hline System network loss cost/10 000 RMB & 9.16 & 83.72 & 643.69 \\
\hline Environmental benefits/10 000 RMB & 709.11 & 69.71 \\
\hline Annual comprehensive income/10 000 RMB & & 625.81 \\
\hline
\end{tabular}

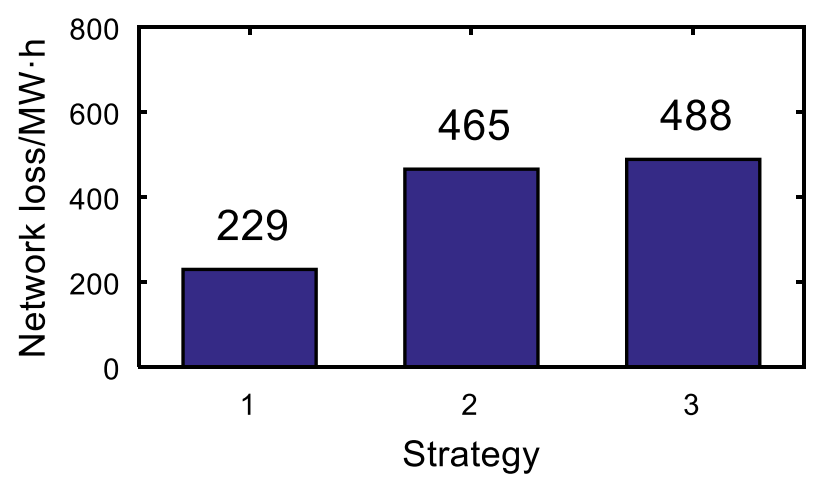

T A B L E 7 Clean energy acceptance and pollutant reduction

\begin{tabular}{llll} 
& Strategy 2 & Strategy 3 \\
\hline Distributed generation total consumption $(\mathrm{MW} \cdot \mathrm{h})$ & Strategy 1 & 12407 & 10127 \\
\hline Electric vehicle charging load total acceptance $(\mathrm{MW} \cdot \mathrm{h})$ & 3692 & 3607 & 3543 \\
$\mathrm{SO}_{2}$ emission reduction $(\mathrm{kg})$ & 44506 & 37799 & 36326 \\
$\mathrm{NO}_{x}$ emission reduction $(\mathrm{kg})$ & 19157 & 16270 & 6.83 \\
\hline Carbon emission reduction $\left(\times 10^{6} \mathrm{~kg}\right)$ & 8.03 & 636 \\
\hline
\end{tabular}

F I G U RE 7 Annual network loss of different strategies 
F I G U R E 8 Maximum voltage shift of IEEE-33 node system

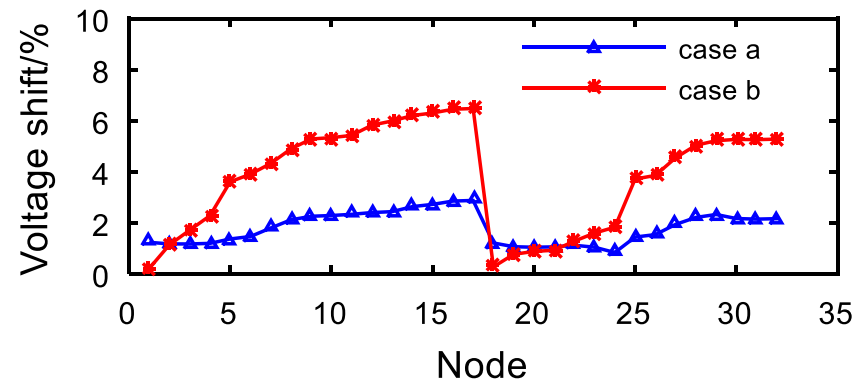

F I G U RE 9 Maximum offset of node voltage

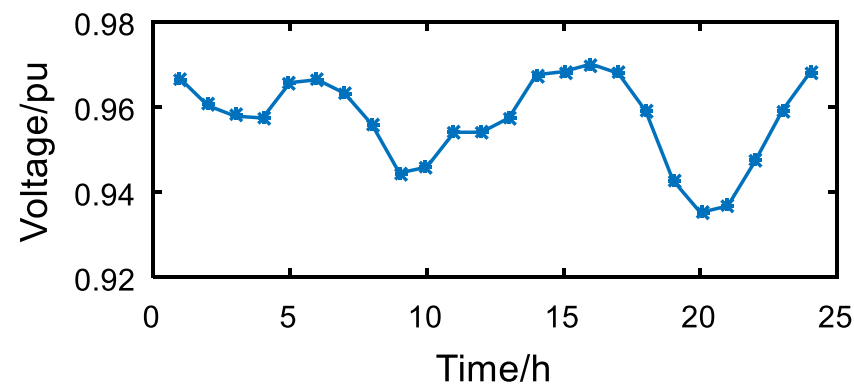

F I G U RE 10 PG\&E-69 node test system

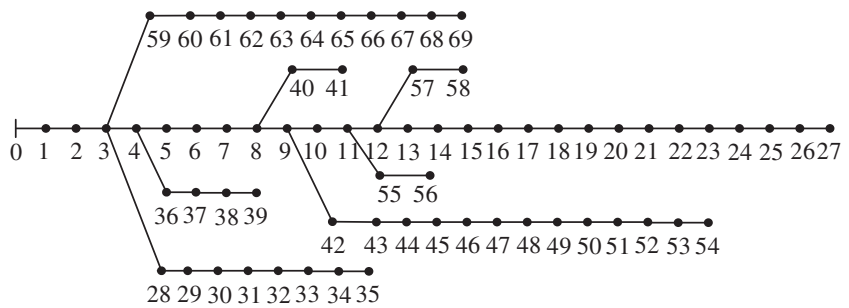

F I G U R E 11 Real 30-node distribution system

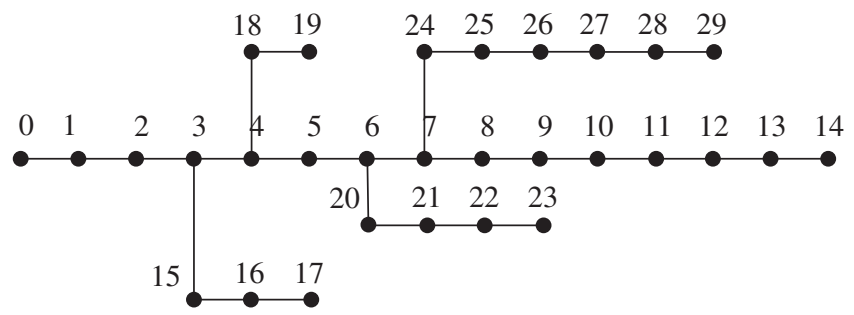

As seen by comparing the optimal allocation results of the three strategies and the annual comprehensive benefits of the distribution network, strategy 1 has the highest level of clean energy acceptance and the best annual comprehensive benefits. A comparison of the advantages and disadvantages of the three strategies is similar to the simulation results of the IEEE-33 node test system. The proposed model is verified again based on the optimal configuration results of the PG\&E-69 node system and a real 30-node distribution system.

\section{3 | Performance comparison of algorithms}

In this article, the IHPSO algorithm and the PSO algorithm are tested by the test functions $f_{1}(x) \sim f_{4}(x)$.

$$
f_{1}(x)=\sum_{i=1}^{n} x_{i}^{2}
$$




\begin{tabular}{|llll|}
\hline Strategy & \multicolumn{2}{l}{ Optimise configuration results } & Capacity (kW) \\
\hline Strategy 1 & DG & $10(9) .33(2) .38(10) .21(3) .50(10) .66(10)$ & 4400 \\
& EVCS & $14(186) .32(273) .40(190) .45(266) .61(339)$ & 1254 \\
\hline Strategy 2 & DG & $10(2) .33(5) .38(10) .21(4) .50(10) .66(10)$ & 4100 \\
& EVCS & $14(185) .32(294) .40(238) .45(224) .61(214)$ & 1155 \\
\hline Strategy 3 & DG & $10(5) .33(2) .38(10) .21(2) .50(9) \cdot 66(9)$ & 3700 \\
& EVCS & $14(190) .32(181) .40(193) .45(188) .61(191)$ & 943 \\
\hline
\end{tabular}

T A B L E 8 Optimal allocation results of different strategies for the PG\&E-69 node system

Abbreviations: DG, distributed generation; EVCS, electric vehicle charging stations.

TA B LE 9 The active management measures of strategy 1 in the PG\&E-69 node system

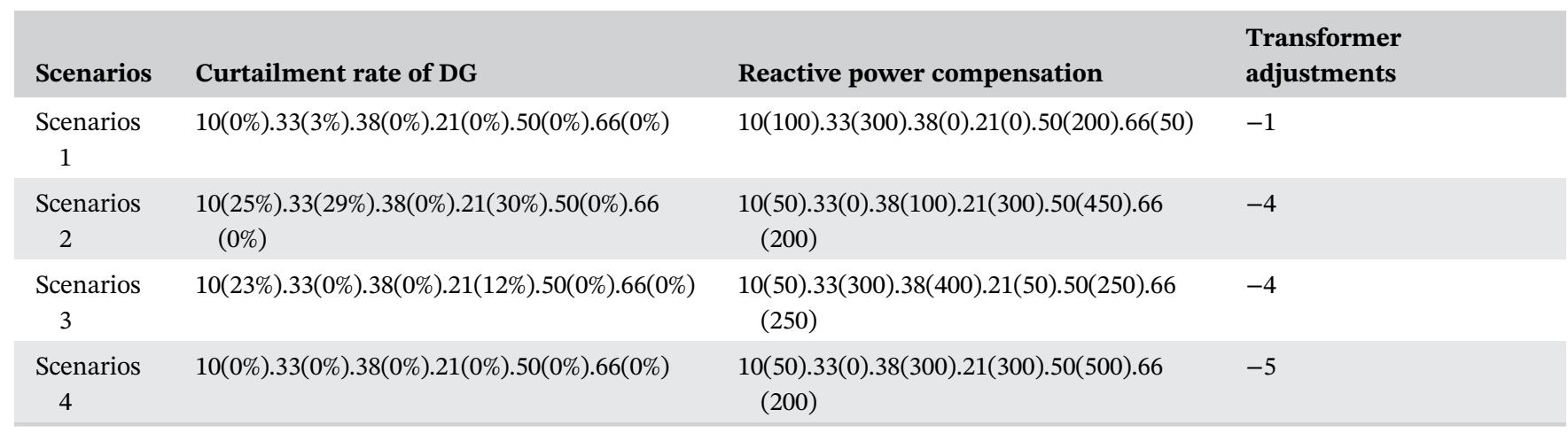

T A B L E 10 Comprehensive income of different strategies for the PG\&E-69 node system

\begin{tabular}{|c|c|c|c|}
\hline & Strategy 1 & Strategy 2 & Strategy 3 \\
\hline Operation and maintenance cost/10 $000 \mathrm{RMB}$ & 39.83 & 35.66 & 33.02 \\
\hline Government subsidy fee/10 $000 \mathrm{RMB}$ & 194.31 & 189.02 & 169.32 \\
\hline Distribution network sales revenue/10 $000 \mathrm{RMB}$ & 652.76 & 614.36 & 592.47 \\
\hline Charging station sales revenue/10 $000 \mathrm{RMB}$ & 260.75 & 258.63 & 248.98 \\
\hline System network loss cost/10 $000 \mathrm{RMB}$ & 2.73 & 4.57 & 4.30 \\
\hline Environmental benefits/10 $000 \mathrm{RMB}$ & 77.34 & 71.53 & 67.90 \\
\hline Annual comprehensive income/10 $000 \mathrm{RMB}$ & 687.17 & 661.04 & 641.33 \\
\hline
\end{tabular}

T A B LE 11 Optimal allocation results of different strategies for the 30-node system

\begin{tabular}{|c|c|c|c|}
\hline \multirow{2}{*}{$\begin{array}{l}\text { Strategy } \\
\text { Strategy } 1\end{array}$} & \multicolumn{2}{|c|}{ Optimise configuration results } & \multirow{2}{*}{$\begin{array}{l}\text { Capacity (kW) } \\
16800\end{array}$} \\
\hline & DG & 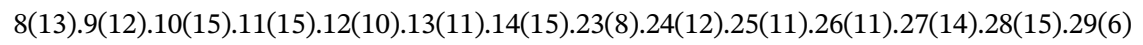 & \\
\hline & EVCS & $5(470) \cdot 8(494) \cdot 16(562) \cdot 22(372) \cdot 25(660)$ & 2258 \\
\hline Strategy 2 & EVCS & $5(454) \cdot 8(537) \cdot 16(316) \cdot 22(482) \cdot 25(203)$ & 1992 \\
\hline Strategy 3 & DG & $8(14) \cdot 9(14) \cdot 10(14) \cdot 11(7) \cdot 12(13) \cdot 13(14) \cdot 14(14) \cdot 23(2) \cdot 24(6) \cdot 25(7) \cdot 26(3) \cdot 27(8) \cdot 28(3) \cdot 29(7)$ & 12600 \\
\hline
\end{tabular}

Abbreviations: DG, distributed generation; EVCS, electric vehicle charging stations. 
TA B LE 12 The active management measures of strategy 1 in the 30-node system

\begin{tabular}{|c|c|c|c|}
\hline Scenarios & Curtailment rate of distributed generation & Reactive power compensation & $\begin{array}{l}\text { Transformer } \\
\text { adjustments }\end{array}$ \\
\hline $\begin{array}{l}\text { Scenarios } \\
1\end{array}$ & $\begin{array}{c}8(0 \%) \cdot 9(0 \%) \cdot 10(0 \%) \cdot 11(0 \%) \cdot 12(0 \%) \cdot 13(0 \%) \cdot 14(0 \%) \cdot 23 \\
\quad(0 \%) \cdot 24(0 \%) \cdot 25(0 \%) \cdot 26(0 \%) \cdot 27(0 \%) \cdot 28(0 \%) \cdot 29(0 \%)\end{array}$ & $\begin{array}{l}8(0) \cdot 9(0) \cdot 10(450) \cdot 11(200) \cdot 12(200) \cdot 13(100) \cdot 14 \\
\quad(350) \cdot 23(0) \cdot 24(100) \cdot 25(250) \cdot 26(200) \cdot 27(0) \cdot 28 \\
\quad(350) \cdot 29(50)\end{array}$ & -3 \\
\hline $\begin{array}{l}\text { Scenarios } \\
\quad 2\end{array}$ & $\begin{array}{l}8(30 \%) \cdot 9(0 \%) \cdot 10(0 \%) \cdot 11(0 \%) \cdot 12(0 \%) \cdot 13(28 \%) \cdot 14 \\
\quad(0 \%) \cdot 23(30 \%) \cdot 24(11 \%) \cdot 25(30 \%) \cdot 26(30 \%) \cdot 27(30 \%) \cdot 28 \\
\quad(25 \%) \cdot 29(30 \%)\end{array}$ & $\begin{array}{l}8(0) \cdot 9(100) \cdot 10(350) \cdot 11(0) \cdot 12(500) \cdot 13(50) \cdot 14 \\
\quad(150) \cdot 23(150) \cdot 24(0) \cdot 25(300) \cdot 26(500) \cdot 27(450) \cdot 28 \\
\quad(100) \cdot 29(150)\end{array}$ & 0 \\
\hline $\begin{array}{l}\text { Scenarios } \\
\quad 3\end{array}$ & $\begin{array}{l}8(0 \%) \cdot 9(0 \%) \cdot 10(0 \%) \cdot 11(0 \%) \cdot 12(0 \%) \cdot 13(0 \%) \cdot 14(0 \%) \cdot 23 \\
\quad(16 \%) \cdot 24(0 \%) \cdot 25(0 \%) \cdot 26(30 \%) \cdot 27(0 \%) \cdot 28(30 \%) \cdot 29 \\
\quad(0 \%)\end{array}$ & $\begin{array}{l}8(0) \cdot 9(0) \cdot 10(300) \cdot 11(250) \cdot 12(200) \cdot 13(0) \cdot 14(0) \cdot 23 \\
\quad(400) \cdot 24(0) \cdot 25(500) \cdot 26(500) \cdot 27(0) \cdot 28(0) \cdot 29(0)\end{array}$ & 1 \\
\hline $\begin{array}{l}\text { Scenarios } \\
\quad 4\end{array}$ & $\begin{array}{c}8(0 \%) \cdot 9(0 \%) \cdot 10(0 \%) \cdot 11(0 \%) \cdot 12(8 \%) \cdot 13(0 \%) \cdot 14(0 \%) \cdot 23 \\
\quad(0 \%) \cdot 24(0 \%) \cdot 25(0 \%) \cdot 26(0 \%) \cdot 27(0 \%) \cdot 28(0 \%) \cdot 29(0 \%)\end{array}$ & $\begin{array}{l}8(400) \cdot 9(300) \cdot 10(50) \cdot 11(500) \cdot 12(0) \cdot 13(250) \cdot 14 \\
\quad(0) \cdot 23(0) \cdot 24(250) \cdot 25(400) \cdot 26(0) \cdot 27(0) \cdot 28(350) \cdot 29 \\
\quad(0)\end{array}$ & -5 \\
\hline
\end{tabular}

T A B L E 13 Comprehensive income of different strategy for the 30-node system

\begin{tabular}{|c|c|c|c|}
\hline & Strategy 1 & Strategy 2 & Strategy 3 \\
\hline Investment and construction cost/10 $000 \mathrm{RMB}$ & 1179.19 & 986.11 & 932.71 \\
\hline Operation and maintenance cost/10 $000 \mathrm{RMB}$ & 144.66 & 139.00 & 134.19 \\
\hline Distribution network sales revenue/10 $000 \mathrm{RMB}$ & 2782.24 & 2674.26 & 2602.63 \\
\hline Charging station sales revenue/10 $000 \mathrm{RMB}$ & 525.06 & 491.60 & 496.00 \\
\hline System network loss cost/10 $000 \mathrm{RMB}$ & 27.75 & 44.65 & 46.48 \\
\hline Environmental benefits/10 $000 \mathrm{RMB}$ & 299.66 & 282.30 & 271.77 \\
\hline Annual comprehensive income/10 $000 \mathrm{RMB}$ & 2981.13 & 2873.41 & 2809.21 \\
\hline
\end{tabular}

$$
\begin{gathered}
f_{2}(x)=\sum_{i=1}^{n}\left|x_{i}\right|+\prod_{i=1}^{n}\left|x_{i}\right| \\
f_{3}(x)=\sum_{i=1}^{n-1}\left[100 \cdot\left(x_{i+1}-x_{i}^{2}\right)^{2}+\left(x_{i}-1\right)^{2}\right] \\
f_{4}(x)=\sum_{i=1}^{n}\left[x_{i}^{2}-10 \cdot \cos \left(2 \pi x_{i}\right)+10\right] .
\end{gathered}
$$

The search parameters of the functions $f_{1}(x) \sim f_{4}(x)$ are shown in Table 14.

Using MATLAB programming, the particle swarm size of the algorithm is 50 , the number of iterations is 1000 , and each algorithm runs 100 times independently. The test results of the two algorithms are shown in Table 15.

According to the simulation results of the $f_{1}(x)$ function, the IHPSO algorithm is superior to the PSO algorithm in searching for single-peak convex functions. Compared with the PSO algorithm, the IHPSO algorithm has a stronger global searching ability for functions with local extrema such as $f_{2}(x)$ and $f_{3}(x)$. Therefore, the indexes of simulation results have been greatly improved. For functions such as $f_{4}(x)$, for which it is difficult to search for global extrema, the simulation results again verify the IHPSO search. It can be verified that the IHPSO algorithm proposed in this article substantially improves the performance of the algorithm. 

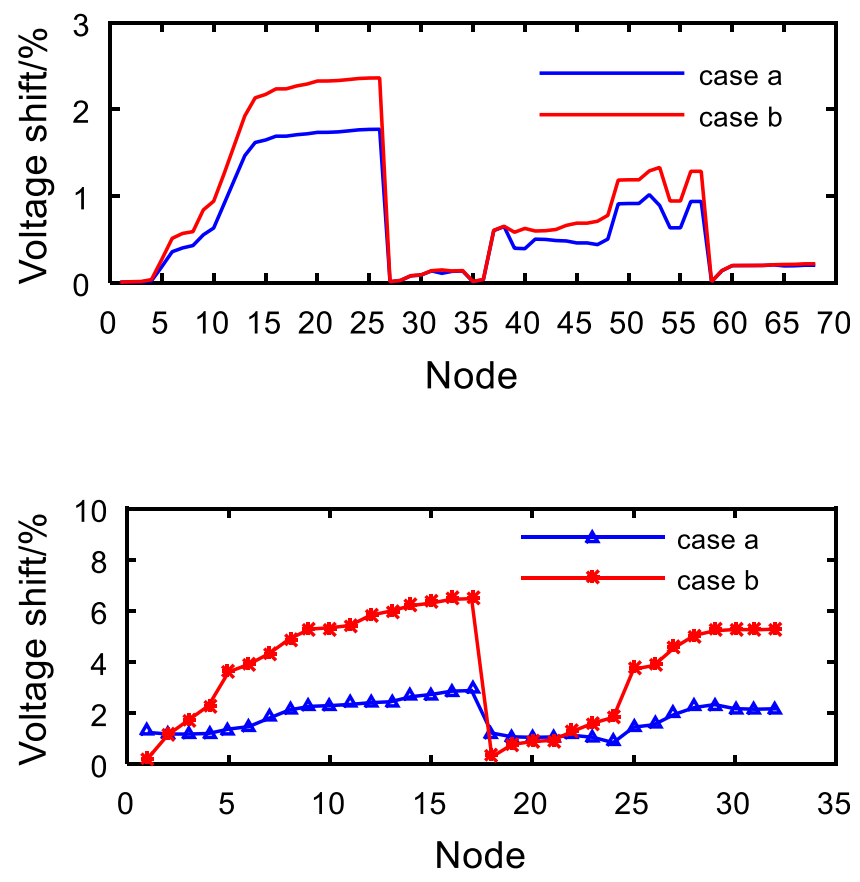

F I G U RE 12 Maximum voltage shift of the PG\&E-69 node system

F I G URE 13 Maximum voltage shift of the regional 30-node system

\begin{tabular}{llll} 
Function & Dimension & Search scope & Theoretical optimum \\
\hline$f_{1}$ & 10 & {$[-100100]$} & 0 \\
$f_{2}$ & 10 & {$[-100100]$} & 0 \\
$f_{3}$ & 10 & {$[-100100]$} & 0 \\
$f_{4}$ & 10 & {$[-100100]$} & 0 \\
\hline
\end{tabular}

\begin{tabular}{|lllll|}
\hline Function & Algorithm & Best value & Worst value & Mean value \\
\hline$f_{1}$ & PSO & $5.117 \mathrm{e}-20$ & $3.017 \mathrm{e}-04$ & $3.246 \mathrm{e}-06$ \\
& IHPSO & $1.687 \mathrm{e}-20$ & $1.660 \mathrm{e}-07$ & $4.1975 \mathrm{e}-09$ \\
\hline$f_{2}$ & PSO & 0.053 & 47.321 & 7.126 \\
& IHPSO & $7.310 \mathrm{e}-04$ & $1.830 \mathrm{e}-01$ & $2.316 \mathrm{e}-02$ \\
\hline$f_{3}$ & PSO & $3.965 \mathrm{e}-04$ & 469.222 & 29.459 \\
& IHPSO & $7.685 \mathrm{e}-05$ & 18.008 & 3.242 \\
\hline$f_{4}$ & PSO & 0.995 & 46.763 & 15.900 \\
& IHPSO & 0.995 & 16.914 & 6.779 \\
\hline
\end{tabular}

Abbreviations: IHPSO, improved harmonic particle swarm optimisation; PSO, particle swarm optimisation.
T A B L E 14 Function search parameters

T A B L E 15 Algorithm simulation results

\section{6 | CONCLUSION}

This article proposes a bi-level optimal allocation model for DG and EVCSs with consideration of the variability and stochasticity of the EV charging load, the DG output power and the conventional load. The model is solved by the IHPSO algorithm. Some conclusions can be summarised as follows:

1. Under the assumption that countries attach importance to the development of clean energy DG and EVs, compared to the independent planning of DG, the coordination and complementarity between the charging load and DG should be considered when optimising the allocation of DG, which is conducive to promoting the absorption of clean energy in the system. 
2. The use of an active management strategy can result in more reasonable plans for optimal DG and EVCS allocation, which increases the capacity of DG and EVCSs over that the reliable system already in operation, increases the profit of the power supply company and reduces power loss while making better use of clean energy for emission reductions under the encouragement of the national energy policy.

3. Compared with the traditional PSO algorithm, the IHPSO algorithm established in this article has a strong global optimisation ability, does not easily fall into local optima, and results in improved performance of the algorithm.

\section{ACKNOWLEDGMENTS}

This study was funded by Fujian Natural Science Foundation of China, Grant/Award Number: 2016J01219 and Fujian Scholarship to Study Abroad of 2018.

\section{LIST OF SYMBOLS AND ABBREVIATIONS}

$\begin{array}{ll}\text { Abbreviations } \\ \text { DG } & \text { distributed generation } \\ \text { DWG } & \text { distributed wind generation } \\ \text { EVs } & \text { electric vehicles } \\ \text { EVCSs } & \text { electric vehicle charging station } \\ \text { IHPSO } & \text { improved harmonic particle swarm optimisation } \\ \text { PVG } & \text { photovoltaic generation }\end{array}$

\section{Variables and parameters}

$T_{\mathrm{c}}$

$B$

$S O C_{0}$

$\eta$

$P_{\mathrm{c}}$

$E_{\mathrm{b}}$

$P_{\mathrm{PVG}}$

$P_{\text {PVGS }}$

$g / g_{\mathrm{s}}$

$P_{\text {DWG }}$

$P_{\text {DWGS }}$

$v$

$v_{\mathrm{i}} / v_{\mathrm{o}}$

$\mathrm{v}_{\mathrm{S}}$

$C_{\text {pro }}$

$C_{\text {loss }}$

$C_{\text {env }}$

$C_{\mathrm{s}}$

$C_{\mathrm{B}}$

$C_{\text {inv }}$

$C_{\mathrm{OM}}$

$k$

$p_{l}$

$c_{\mathrm{i}} / c_{\mathrm{o}}$

$c_{\mathrm{e}}$

$P_{l, t, \mathrm{~L}}$

$P_{l, t, \mathrm{DWG}}$

$P_{l, t, \mathrm{PVG}}$

$P_{l, t, \mathrm{EV}}$

$c_{\mathrm{b}, \mathrm{DWG}}$

$c_{\mathrm{b}, \mathrm{PVG}}$ charging time in minutes

percentage of batter capacity after charging

percentage of battery capacity before charging

charging efficiency

charging power

battery capacity

output power of PV

rated output power of PV

actual/rated solar irradiance

wind output power

rated wind output power

actual wind speed

cut-in/cut-off wind speed

rated wind speed

annual rate of return for the power supply company

power loss

environmental and social welfare

profit of the power supply company

government subsidies for renewable energy sources

investment in intermittent DG and EVCSs

maintenance fee for DG and EVCSs

number of typical scenarios

probability of the $l$ th typical scenario

purchasing/selling prices for the power supply company

unit selling price for EVCSs

load demand at time interval $t$

DWG output power at time interval $t$

PVG active power at time interval $t$

EVCS charging load at time interval $t$

units of government subsidies for DWG

units of government subsidies for PVG 


\begin{tabular}{|c|c|}
\hline$C_{\text {inv }}$ & investment and building costs of DG and EVCSs \\
\hline$n_{\mathrm{DWG}}$ & number of candidate nodes for DWG \\
\hline$n_{\mathrm{PVG}}$ & number of candidate nodes for PVG \\
\hline$n_{\mathrm{EV}}$ & number of candidate nodes for EVCSs \\
\hline$P_{j, \mathrm{DWG} /} P_{j, \mathrm{PVG} /} P_{j, \mathrm{EV}}$ & capacity for DWG/PVG/EVCSs at node $j$ \\
\hline$c_{\mathrm{t} 1 /} c_{\mathrm{t} 2 /} c_{\mathrm{t} 3}$ & unit capacity construction costs of DWG/PVG/EVCSs \\
\hline$c_{\mathrm{g}}$ & fixed investment cost of EVCSs \\
\hline$r$ & discount rate \\
\hline$n_{1}$ & service life of the equipment \\
\hline$c_{\mathrm{om} 1} / c_{\mathrm{om} 2}$ & unit maintenance fees for DWG/PVG \\
\hline$c_{\mathrm{om} 3}$ & amortised unit maintenance fee for EVCSs \\
\hline$P_{l, t, \text { loss }}$ & system loss at time interval $t$ \\
\hline$E_{\mathrm{S}}$ & output power for renewable energy \\
\hline$C_{\mathrm{env}}$ & social welfare of renewable energy sources and reduced emissions from EVs \\
\hline$N_{\text {env }}$ & types of pollution gases \\
\hline$x_{s} / a_{s} / b_{s}$ & emission levels of the sth kind of pollution gas \\
\hline$e_{\mathrm{EV}}$ & energy consumed by an EV in 100 miles \\
\hline$c_{\mathrm{CO}_{2}}$ & $\mathrm{CO}_{2}$ trading tax fee in the international market \\
\hline$x_{\mathrm{EV}}$ & difference between EVs and conventional vehicles \\
\hline$C_{l, \mathrm{~S}}$ & profit of the power supply company in scenario $l$ \\
\hline$C_{l, \mathrm{~B}}$ & government subsidy for renewable energy sources in scenario $l$ \\
\hline$C_{l, \mathrm{OM}}$ & maintenance fee for DG and EVCSs in scenario $l$ \\
\hline$C_{l, \text { loss }}$ & power loss fee in scenario $l$ \\
\hline$C_{l, \mathrm{env}}$ & social welfare in scenario $l$ \\
\hline$P_{i} / Q_{i}$ & active/reactive power injections \\
\hline$U_{i} / U_{j}$ & voltages at nodes $i$ and $j$ \\
\hline$G_{i j} / B_{i j}$ & conductance and admittance \\
\hline$\theta_{i j}$ & angle shift between $i$ and $j$ \\
\hline$U_{i \max } / U_{i \min }$ & upper/lower voltage bounds at node $i$ \\
\hline$S_{i j}$ & transmission power \\
\hline$S_{i j \max }$ & transmission power limit \\
\hline$U_{\text {OLTC }}$ & secondary voltage at the transformer \\
\hline$U_{\text {OLTC }}^{\max } / U_{\text {OLTC }}^{\min }$ & upper/lower limits of secondary voltage at the transformer \\
\hline$P_{\text {cuti }}$ & curtailment for DG at node $i$ \\
\hline$P_{\text {cut } i}^{\max }$ & allowed curtailment at node $i$ \\
\hline$Q_{c i}$ & reactive power compensation at node $i$ \\
\hline$Q_{\mathrm{ci}}^{\max }$ & allowed upper limit of reactive power compensation at node $i$ \\
\hline$x_{i, j}$ & $j$-dimension of particle $i$ \\
\hline$x_{j}^{\max } / x_{j}^{\min }$ & upper and lower limit values of variable $j$ \\
\hline$\chi_{i, j}$ & sequences of chaotic variables generated by logistic mode 1 \\
\hline$\lambda$ & chaotic parameters \\
\hline$K$ & number of clusters \\
\hline$S$ & number of original scene samples \\
\hline $\operatorname{tr}\left(N_{\mathrm{B}}\right) / \operatorname{tr}\left(N_{\mathrm{W}}\right)$ & traces of the interclass and intraclass scatter matrices \\
\hline
\end{tabular}

\section{ORCID}

Lijun Liu (D) https://orcid.org/0000-0002-8074-6819

\section{REFERENCES}

1. Zhao J, Xu Z, Wang JH. Robust distributed generation investment accommodating electric vehicle charging in a distribution network. IEEE Trans Power Syst. 2018;33(5):4654-4666.

2. Wang L, Sharkh S, Chipperfield A. Optimal decentralized coordination of electric vehicles and renewable generators in a distribution network using A* search. Int J Electr Power Energy Syst. 2018;98:474. 
3. Gao YJ, Liu JP, Yang J, et al. Multi-objective planning of multi-type distributed generation considering timing characteristics and environmental benefits. Power Syst Protect Control. 2014;7(10):6242-6257.

4. Kayalvizhi S, KDM V. Optimal planning of active distribution networks with hybrid distributed energy resources using grid-based multiobjective harmony search algorithm. Appl Soft Comput. 2018;67:387.

5. Singh B, Mukherjee V, Tiwari P. GA-based multi-objective optimization for distributed generations planning with DLMs in distribution power systems. J Electr Syst Inf Technol. 2016;4:1311.

6. Xiang Y, Liu JY, Li R. Economic planning of electric vehicle charging stations considering traffic constraints and load profile templates. Appl Energy. 2016;178:647-659.

7. Yan XW, Duan C, Chen X. Planning of electric vehicle charging station based on hierarchic genetic algorithm. Transportation Electrification Asia-Pacific. IEEE; 2014:1-5.

8. Bayati M, Abedi M, Gharehpetian GB, Farahmandrad M. Short-term interaction between electric vehicles and microgrid in decentralized vehicle-to-grid control methods. Protect Control Modern Power Syst. 2019;4(4):42-52.

9. Yao W, Zhao J, Wen F. A multi-objective collaborative planning strategy for integrated power distribution and electric vehicle charging systems. IEEE Trans Power Syst. 2014;29(4):1811-1821.

10. Liu JP, Zhang TX, Zhu J, Ma TN. Allocation optimization of electric vehicle charging station (EVCS) considering with charging satisfaction and distributed renewables integration. Energy. 2018;164(1):560-574.

11. Shojaabadi S, Abapour S, Abapour M. Simultaneous planning of plug-in hybrid electric vehicle charging stations and wind power generation in distribution networks considering uncertainties. Renew Energy. 2016;99:237-252.

12. Kandil SM, Farag HEZ, Shaaban MF. A combined resource allocation framework for PEVs charging stations, renewable energy resources and distributed energy storage systems. Energy. 2018;143(15):961-972.

13. Zare K, Abapour S, Mohammadi-Ivatloo B. Dynamic planning of distributed generation units in active distribution network. IET Generat Transm Distrib. 2015;9(12):1455-1463.

14. Bo Z, Nian L, Yuying Z, et al. Bi-level scenario programming of active distribution network for promoting intermittent distributed generation utilization. Trans China Electrotech Soc. 2013;28:155.

15. Islam MS, Nadarajah M, Duong QH. A day-ahead forecasting model for probabilistic EV charging loads at business premises. IEEE Trans Sustain Energy. 2018;9:741-753.

16. Luo Z, Hu Z, Song Y. Study on plug-in electric vehicles charging load calculating. Autom Electr Power Syst. 2011;35(14):36-42.

17. Zhang Hepner GF. The dynamic-time-warping-based K-means++ clustering and its application in phenoregion delineation. Int J Remote Sens. 2017;38(6):1720-1736.

18. Vogel MA, Wong AKC. PFS clustering method. IEEE Trans Pattern Anal Mach Intell. 2009;PAMI-1(3):237-245.

19. Zhang J, Li KJ, Wang M, et al. A bi-level program for the planning of an islanded microgrid including CAES. IEEE Trans Ind Appl. 2016;52(4):2768-2777.

20. Asensio M, Munoz-Delgado G, Contreras J. A bi-level approach to distribution network and renewable energy expansion planning considering demand response. IEEE Trans Power Syst. 2017;32(6):4298-4309.

21. Baran ME, Wu FF. Network reconfiguration in distribution systems for loss reduction and load balancing. IEEE Trans Power Deliv. 1989;4(2):1401-1407.

22. Grigg C. The IEEE reliability test system 1996. IEEE Trans Power Syst. 1999;14(3):1010-1020.

23. Yan Y, Wu W, Zhang Y. Optimal allocation of intermittent distributed generation in considering benefit of regional energy active distribution network supplier. Power Syst Technol. 2017;41(3):752-758.

24. Su H, Hu M, Liang Z. Distributed generation \& energy storage planning based on timing haracteristics. Electric Powcr Autom Equip. 2016;36(6):56-63.

25. Baran ME, Wu FF. Optimal capacitor placement on radial distribution systems. IEEE Trans Power Deliv. 2002;4(1):725-734.

26. Peng X, Lin L, Liu Y, et al. Optimal distributed generator allocation method based on correlation Latin hypercube sampling Monte Carlo simulation embedded crisscross optimization algorithm. Proc CSEE. 2015;35(16):4077-4085.

How to cite this article: Liu L, Zhang Y, Da C, Huang Z, Wang M. Optimal allocation of distributed generation and electric vehicle charging stations based on intelligent algorithm and bi-level programming. Int Trans Electr Energ Syst. 2020;30:e12366. https://doi.org/10.1002/2050-7038.12366 